\title{
New concept for continuous documentation of development of quality circles in ambulatory care: initial results from an information system in Germany
}

\author{
Ferdinand M Gerlach, Martin Beyer
}

\section{Introduction}

Requested by both governmental and professional organisations, quality circles for physicians involved with ambulatory care began in Germany in the late 1980s (box 1). Development of quality improvement through peer review suited the particular characteristics of the German ambulatory care system (box 2). Physicians who work predominantly in single handed practices and who can feel isolated value the opportunity to work in groups. Rules and guidelines published by the Federal Association of Statutory Health Insurance Physicians (Kassenärztliche Bundesvereinigung, which is an association of physicians caring for patients who are insured through statutory sickness funds) encouraged the role of quality improvment through voluntary instigation of quality circles. ${ }^{2}$

A comprehensive strategy for establishing quality circles and other quality improvement initiatives in ambulatory care was set up by the University Departments for General Practice in Hannover and Göttingen together with the Institute for Applied Quality Improvement and Research in Health Care, Göttingen. From this initiative alone over 750 providers of ambulatory care have been trained as group moderators to set up and coordinate local quality circles. Funding from the Federal Ministry of Health enabled development of an influential handbook on quality circles that included descriptions of experiences from other countries. ${ }^{4}$ Other aspects of the implementation strategy included research projects on quality improvement and the development of manuals, documentation materials, videos, symposia, and regular supervisory meetings for quality circle moderators. ${ }^{56}$ In total there was an increase in the number of quality circles in ambulatory care from 16 in 1993 to over $1630 .^{7}$

An unusual aspect of this project was that it was general practitioners rather than the usually dominating specialists who initiated this development. ${ }^{4}$ Surveys from regional associations indicated that quality circles are generally well accepted. Over half the physicians in ambulatory care are willing to participate in quality circles; one third remain uncertain; but only $10 \%$ are outwardly hostile to participation in peer review.

Although various professional bodies and sickness funds support and encourage the development of quality improvement in ambulatory care, most quality circles have been founded spontaneously by physicians. Some have formed completely new peer review groups, others have transformed other groups such as Balint groups, specialty case conferences, continuing medical education groups, or informal meetings of physicians into quality circles. The particular status of private practice in German health care means that, compared with other European countries, little pressure is applied by purchasers of health care to control quality improvement activities. ${ }^{111}{ }^{12}$ Although this might have encouraged autonomous development of quality improvement little reliable information is available on appraisal of development and impact of the work of quality circles.

We wanted to get standardised information on the work being done in quality circles from objective measurable criteria of groups at all stages of development. Such an instrument might provide useful information for the groups and be used to assess progress in quality improvement in ambulatory care. Getting such information is sensitive, and could be feared as a process of external control, so we describe here our system for obtaining this information. The system was based on feeding back only aggregated information to the associations, but providing more detailed information to the groups about themselves for their own use (fig 1). It is important for those keen to develop quality circles to understand current strengths and deficits as a basis for evaluation of the impact of quality improvement work on the quality of ambulatory care. This could also improve communication among those working in quality improvement.

\section{Development of the form}

Together with nine quality circle moderators we developed a form (appendix) designed to allow comparison of information from heterogeneous quality circles. Each moderator completed the form after each session of their quality circle. Before dissemination the form was pretested in quality circles and revised. Box 3 shows the information collected, which enabled monitoring of the development of quality circles according to the objective criteria set out. We obtained data on 491 meetings of 120 quality circles of ambulatory care physicians working in three German regional associations-Bremen, Schleswig-Holstein, and Westphalia-Lippe-in an 18 month period from January 1995 to July 1996 (box 4). Over 1600 physicians were included in this study. We used the data to describe the work of quality circles and to look for trends in development of quality circles over time. 
- In Germany the term quality circle is often used for groups which are synonymously described as peer review groups elsewhere

- In the context of ambulatory care we follow the definition of Grol and Lawrence who describe peer review as "continuous, systematic and critical reflection on their own and others' performance by a number of colleagues (...), with the aim of achieving a continuous improvement in the quality of patient care. Peer review is then an ongoing process involving the defining of criteria, evaluating performance, and implementing change; it focuses on continuous change (...)"1

- The participation of physicians in quality circles is entirely voluntary. Quality circle moderators (group leaders) receive a two day training course, but are themselves full time physicians

- There are quality circles with members from one speciality - for example, general practitioners working on waiting times in their practices-as well as interdisciplinary groups - for example, anaesthesiologists, dermatologists, and surgeons trying to improve treatment of veins in outpatients. Very few quality circles have started to integrate members from other professions-for example, practice staff, community nurses, psychologists

- Objectives and methods of quality circles have been suggested in guidelines issued by the federal association, ${ }^{2}$ but are decided on autonomously by the individual group. Suggestions for objectives include the description and documentation of an individual practice and comparison with colleagues' practices, the exchange of experiences, quality review of practice performance, and application or critical adaptation of existing guidelines (which are currently not obligatory in Germany). Rigid audits of the procedures and performance of individual practices, as it is performed-for example, in the United Kingdom - is unusual

- Increasing numbers of quality circles (see introduction) have become established in Germany since 1993 (a few pilot groups started as early as 1989) to promote quality improvement in ambulatory care

- An evaluation of the performance of quality circles and impact on the quality of ambulatory care is also proposed in the guidelines, but not yet implemented in most of the 23 regional associations.

Box 1 Quality circles in German ambulatory care: principles and key issues.

\section{Engaging moderators}

Moderators of quality circles were central particpants of this project. Recruitment was encouraged through the three local associations. Regular meetings of quality circle moderators were attended especially by external researchers to explain the project. Participation increased during the study (fig 2) and
- Over 112000 physicians work in private practices (about $85 \%$ in single handed practices)

- Only $41.3 \%$ of the providers of ambulatory care work as general practitioners, $58.7 \%$ are specialists

- Ambulatory care physicians in Germany do not have patient registration lists. Patients have direct access to all specialists

- The situation in ambulatory care is characterised by a fee for service system, high contact rates, and numerous diagnostic and therapeutic interventions

- Ninety per cent of the patients are insured by statutory health insurance. Only $10 \%$ are privately insured

- Physicians in private practice who care for patients insured by the statutory sickness funds are compulsory members in one of 23 regional associations of statutory health insurance physicians, which have an obligation to promote quality improvement in ambulatory care

- In 1993 new federal legislation was enacted that provided a legal framework for quality improvement in the entire healthcare system. This gives quality improvement a high priority in the future. $^{3}$

Box 2 Aspects of the German ambulatory healthcare system.

Briefly the following information was gathered:

- Number and qualification of participants

- Frequency and duration of the meetings

- Themes worked on

- Methods of data collection and presentation of documented results

- Problems and conclusions-such as clinical guidelines formulated by the quality circle

- A self audit performed by the moderator which included an overall judgement of individual sessions, group atmosphere, satisfaction of the participants, factual gain, etc

- Other items included date and time of the meetings, schedules, and invited experts who provided additional information were used to complete the picture of the working processes in the different groups

Box 3 Summary of information derived from forms.

after 18 months $56 \%$ of all quality circles known in the three regions-and $88 \%$ in Bremen-were involved and we had received 491 forms (each reporting single sessions) from 120 different groups (about 13 participants in each quality circles). Almost $10 \%$ of the 16120 physicians within the three associations were participating in this study by July 1996. Among the non-participating quality circles, about $18 \%$ of the physicians were involved in quality circle groups. In Bremen this portion was $36 \%$. 
- Bremen: 1233 physicians in ambulatory care: first documentations January 1995, first quarterly report September 1995

- Schleswig-Holstein: 3975 physicians: first documentations January 1995, first quarterly report November 1995

- Westphalia-Lippe: 10912 physicians: first documentations October 1995, first quarterly report June 1996.

Box 4 The three German regional associations used.

Who are the participants and how often do they meet?

Initially, general practitioners led development of quality circles - in 199315 of the 16 pioneering quality circles were led by general practitioners. ${ }^{4}$ Our data show that now physicians from most ambulatory care specialities in Germany participate in quality circles (table 1) . But many groups are interdisciplinary, and specialties represented by participants cannot be directly compared with numbers in each ambulatory care specialty. Most groups met monthly and about $70 \%$ of the members attended. Sessions lasted about two hours.

\section{What is discussed?}

Table 2 shows the main topics of the quality circle sessions.

Two thirds of session time was used for substantial work on chosen topics; $10 \%$ on methodology of peer review and quality improvement; $15 \%$ on general discussion about ambulatory health care, and only $5 \%$ on formalities. Time spent on clinical topics increased as groups became established. For examples after one year quality circles in Bremen the time spent discussing clinical topics
- Flow chart on the diagnosis and treatment of sore throat (general practitioners)

- Guidelines for drug prescription and non-medical treatment of the common cold (general practitioners)

- Guidelines for the application of allergy testing (dermatologists)

- Diabetes II: checklist for screening for complications and monitoring long term control; criteria for the prescription of antidiabetic drugs (general practitioners and hospital physicians)

- Regular preventive examinations of children: guidelines for application of hip sonography and immunisations (paediatricians)

- Methadone substitution for drug addicts: guidelines for patient selection, harmonisation of procedures in giving methadone (multidisciplinary)

- Outpatient ophthalmological surgery: criteria for patient selection and outcome measurement (anaesthetists, ophthalmologists, and staff).

Box 5 Examples of guidelines and statements from German quality circles (region of Bremen).

had increased from $61 \%$ to $70 \%$ of session time, and time on formalities decreased from $15 \%$ to $5 \%$.

Most work of quality circles was about clinical care and cooperation between ambulatory care physicians. Professional concerns, such as remuneration, were given less attention, suggesting that peer review groups are not merely chatting groups as suspected by some German health politicians. Although legal and economi-

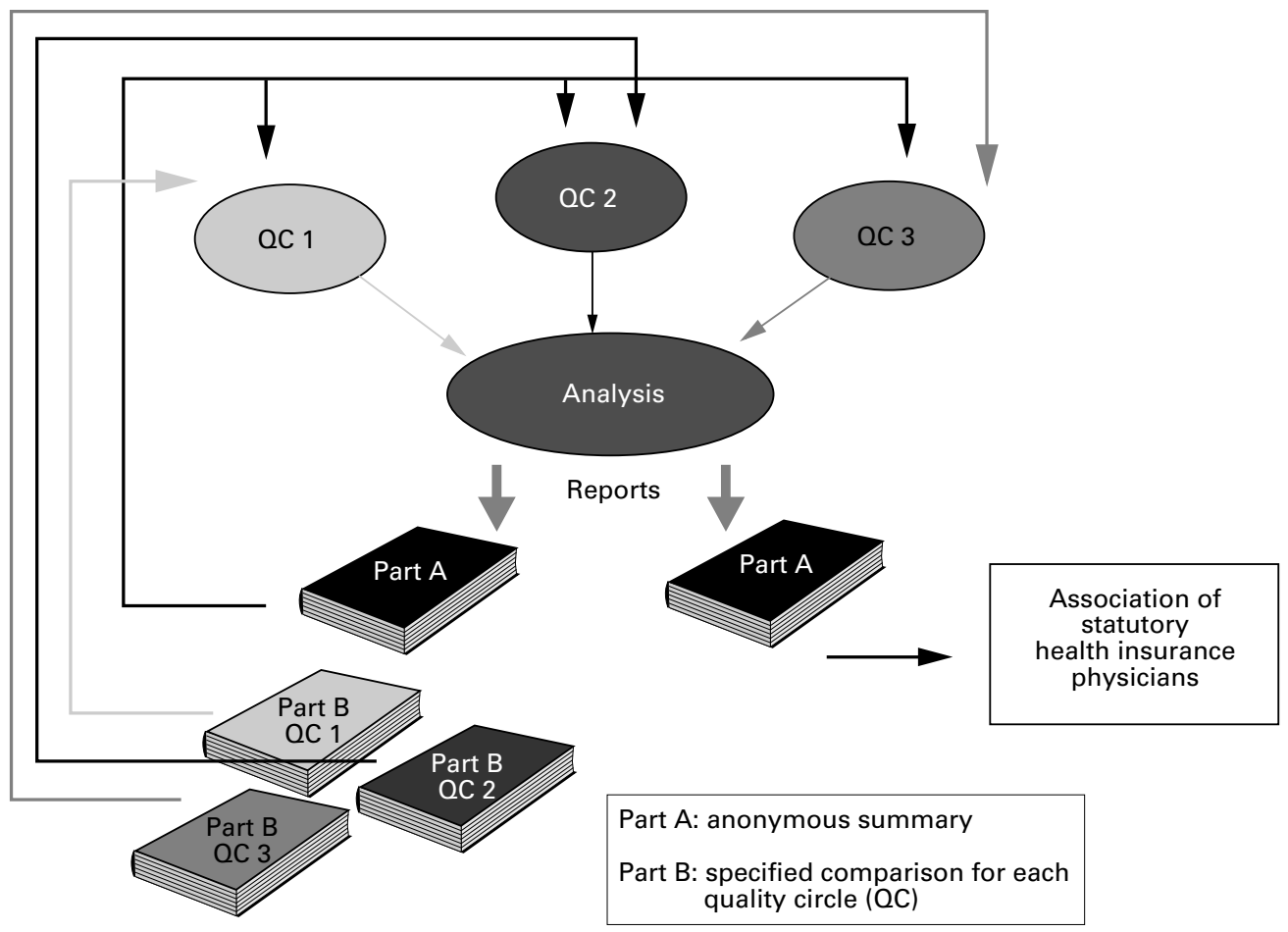

Figure 1 What happens with the data of the documentation form for quality circles? 
Table 1 Quality circles according to medical specialty

\begin{tabular}{lc}
\hline Specialty & $n(\%)$ \\
\hline General practice / family medicine & $28(23.3)$ \\
Internal medicine & $16(13.3)$ \\
Paediatrics & $13(10.8)$ \\
Neurology / psychiatry / psychotherapy & $11(9.2)$ \\
Special treatment / qualification (eg, pain therapy) & $8(6.7)$ \\
Dermatology & $7(5.8)$ \\
Orthopaedics & $5(4.2)$ \\
Other specialisation (eg, anaesthesiology, ophthalmology, radiology) & $5(4.2)$ \\
General topics (eg, problems related to the medical profession) & $5(4.2)$ \\
Internal medicine subspecialities: & $4(3.3)$ \\
Cardiology (2), oncology (1), rheumatology (1) & $4(3.3)$ \\
Surgery & $4(3.3)$ \\
Otorhinolaryngology & $4(3.3)$ \\
Gynaecology & $3(2.5)$ \\
Urology & $3(2.5)$ \\
Information not available & $120(99.9)$ \\
Total & \\
\hline
\end{tabular}

Total

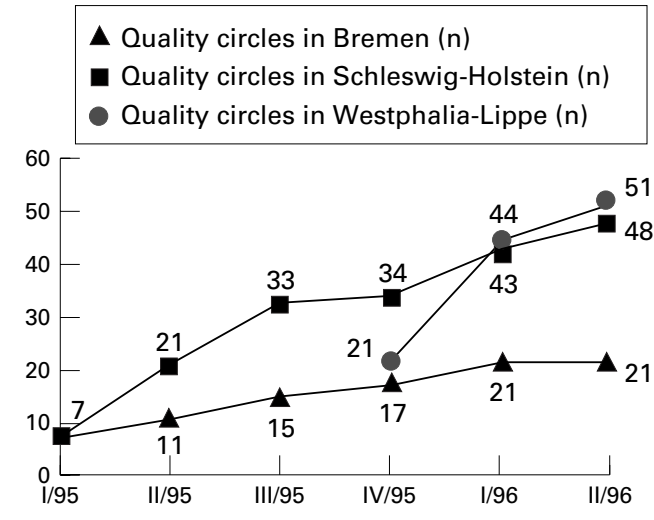

Figure 2 Participating quality circles $(n=120)$.

cal concerns about sickness fund patients were discussed - this was probably linked to changes in the remuneration system, a new fixed budget for drugs in 1995, and announcement of the obligatory use of the ICD-10 classification.

\section{Methods used in quality circles}

Over half of 491 sessions documented and analysed case reports as the focus of discussion. But in over one quarter some discussions included reference to summarised quantitative data. More objective methods-for example, the presentation of computer based practice data-were less often used (table 3). But an increasing use of the collection of objective data derived from the routine practice of individual members was noted over time. For example, in Bremen, in one year, the use of practice records increased from $32 \%$ to $45 \%$,

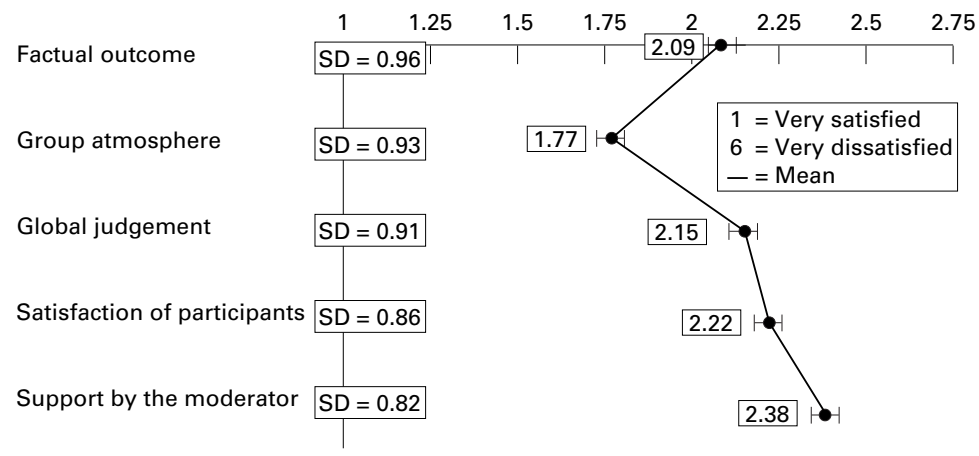

Figure 3 Self audit of quality circle moderators. and the use of documentation forms had doubled from $12 \%$ of the sessions to $23 \%$.

Most new quality circles seem to start by simply exchanging experiences without documentary evidence through either case reports, peer interviews, or problem oriented discussion. Groups then seem gradually to have included objective data collection and analysis. Perhaps this reflects the understanding that documentation and critical evaluation of performance are better bases for quality improvement than theoretical discussions of principles or standards. For many German primary care physicians, work in a quality circle is their first experience of quality improvement methods. From meetings of the moderators it was clear that even some moderators were relatively unfamiliar with methods of quality improvement. Because of this we have set up special courses for moderators on methods of quality improvement that include approaches to documenting and evaluating aspects of clinical care.

\section{Summaries of results}

Over one third of the groups (36\%) summarised results as explicit consensus statements; one fifth produced guidelines; and almost as many produced statements about future work in their practice (box 5). A few quality circles prepared papers or reports on their audit projects for publication to a wider audience. ${ }^{13}$

\section{Feedback of information}

Feedback to the moderators was an essential part of our project. This was done through the Institute for Applied Quality Improvement and Research in Health Care, an independent scientific research group. All moderators and associations received quarterly reports with aggregated summarised information based on data from quality circles in their region. Moderators also received individual feedback (fig 1). They could thus compare the performance of their own group with aggregated data from their region and understand the general development of quality groups.

The format and contents of feedback reports from comments and suggestions of participants became shorter, more readable, and were supplemented with examples of audit reports from quality circles. From a study done in one region-Schleswig-Holstein-on attitudes to this system it seems that most moderators (about 70\%) considered regular reports broadly acceptable and the whole system important. The link with an independent scientific institute was valued. ${ }^{14}$

A literature search did not show any references to comparable information systems for quality circles even in The Netherlands or Ireland, where peer groups are also a widespread phenomenon. Our current approach of monitoring and feedback does serve as a basis for improving the methods used in quality circles. The experiences to date suggest that monitoring quality circles with regular feedback provides support for health professionals working in quality improvement and for those developing quality circles. Identification of 
Table 2 Main topics of quality circle sessions

\begin{tabular}{|c|c|}
\hline Topics & $\begin{array}{l}\text { Sessions } n \\
(\%)\end{array}$ \\
\hline General professional qualifications: & $12(2.8)$ \\
\hline $\begin{array}{l}\text { With respect to the patient-eg, doctor-patient relationship, elementary } \\
\text { treatment of psychosomatic disorders, care of special groups (children, } \\
\text { geriatric patients) }\end{array}$ & $4(0.9)$ \\
\hline With respect to cooperation in healthcare team & $5(1.2)$ \\
\hline Practice management & $3(0.7)$ \\
\hline Medical problems: & $332(77.8)$ \\
\hline Symptoms, patient complaints & $35(8.2)$ \\
\hline Diseases & $107(25.1)$ \\
\hline Diagnostics (techniques) & $19(4.4)$ \\
\hline $\begin{array}{l}\text { Treatments - eg, rational pharmacotherapy, specific treatment techniques, } \\
\text { alternative treatment (physiotherapy, chiropractice, homeopathy) }\end{array}$ & $111(26.0)$ \\
\hline Complex problems of care-eg, chronic disease patients, outpatient-inpatient & \\
\hline $\begin{array}{l}\text { Interrace, adaicted patients, etc } \\
\text { Psychosocial problems }\end{array}$ & $\begin{array}{r}20(4.1) \\
1(0.2)\end{array}$ \\
\hline Psychotherapy & $36(8.4)$ \\
\hline Clinical research & $3(0.7)$ \\
\hline Problems typical for contract physicians or related to the medical profession: & $68(15.9)$ \\
\hline Cooperation with other care providers & $6(1.4)$ \\
\hline $\begin{array}{l}\text { Legal and economical problems of care provision to sickness fund } \\
\text { patients-eg, remuneration, limitations of drug prescription and services } \\
\text { under global budget, practice or prescription audit by the associations, } \\
\text { cutbacks }\end{array}$ & $46(10.8)$ \\
\hline Professional politics & $1(0.2)$ \\
\hline Professional association & $1(0.2)$ \\
\hline Methods of quality improvement & $14(3.3)$ \\
\hline Other / not classified & $15(3.5)$ \\
\hline Total & $427(100.0)^{\star}$ \\
\hline
\end{tabular}

^64 Missing values (13.0\% from 491 sessions).

deficits increased efforts to set up quality improvement in neglected areas and to increase support among established groups.

Various channels were used to get information to moderators who met regularly to discuss development of quality circles. Several were keen to exchange experiences with groups in other regions as well as similar initiatives in German speaking parts of Austria and Switzerland. To facilitate this we have developed a database called "Infoservice Quality Circle" to which quality circles can join voluntarily. Over 135 quality circles have now registered and information about quality improvement initiatives in many specialties and areas are now available

\section{Moderators' view of the work of quality circles}

The moderators indicated their view of the sessions with five six-point Likert type scales with 1 indicating satisfaction and 6 dissatisfaction. ${ }^{15}$ They gave best ratings to group atmosphere, and also rated factual outcome and satisfaction of participants highly. But they rated their own roles and their impact on the group work with more restraint (fig 3 ).

Table 3 Methods for practice documentation (responses to multiple choices from 491 sessions of 120 quality circles)

\begin{tabular}{lc}
\hline Methods & Sessions $n(\%)$ \\
\hline Oral (case) reports & $389(79.2)$ \\
(Peer) interview of physicians or staff & $243(49.5)$ \\
Computer based practice data & $117(23.8)$ \\
Practice records & $106(21.6)$ \\
Documentation sheets & $85(17.3)$ \\
Referral letters / reports & $56(11.4)$ \\
Participatory observation / practice visits & $56(11.4)$ \\
Patient interviews & $31(6.3)$ \\
Video documentation & $20(4.1)$ \\
Audio documentation & $4(0.8)$ \\
Other methods & $103(21.0)$ \\
& \\
Total & 1210 \\
\hline
\end{tabular}

\section{Reflection}

With a simple questionnaire we have managed to get a picture of the development of the increasing number of quality circles in ambulatory care in three regions in Germany, and to support a continuous flow of data. Understanding different rates of development will help associations to form a strategy for evaluation of the performance of peer review groups in German health care. By feeding back data to the participants, the forms also had an active communicative function. Participants were able to look closely at their own function and compare themselves with other groups.

Even though information was limited there continues to be concern about official control and infringement on professional autonomy, and many moderators-even within the three regions in this study - remain reluctant to contribute. The reasons were not clear but possibly relate to fear of control by the sickness fund or concern about having to present their own work to others.

A carefully considered feedback system ensures that rights of individual care providers and patients are not infringed by storage of personalised data on computer. This remains a highly sensitive issue in Germany. We have also had to ensure that there is no encroachment on physicians' autonomy by mandatory guidelines or external practice audits. Associations do not urge physicians to undertake quality improvement. A form that does not include questions about performance or changes in the participants' own practice does, to some extent, limit the comprehensiveness of data and although we have been able to describe the development of quality circles we cannot measure the contributition of this work on quality improvement to actual patient care. We remain reliant on the scientific literature for evidence that quality circles can improve clinical care. ${ }^{111121617}$ Getting further information depends on the willingness of moderators to present the results of quality circle work or to add further remarks to the form.

Participation in quality circles is voluntary. Associations do encourage quality circles, particularly in neglected areas. Participation by all medical specialties and the establishment of interdisciplinary quality circles suggest that the problems about cooperation between different providers and other issues central to ambulatory care - for example, home care, outpatient surgery-may be becoming the focus of discussion by these groups. But it remains unusual for practice staff, nurses, or other health professionals to be involved in quality circles. We consider this a major barrier to performing a real practice audit within the quality circles.

So far, our information system describes few performance indicators of quality circles. We now use an additional questionnaire to assess how far groups meet established criteria for quality circle work (box 1). ${ }^{2}$ Information from a series of sessions from individual quality circles will permit a five stage categorisation of the degree to which quality circle criteria are met. Information will also include the structure and 
stability of groups, the setting of objectives and constancy of work, and the use of appropriate documentation and evaluation of individual practice. From this we expect to describe development of the work of groups-for example, ranging from "no practice audit possible" to "full practice audit performed"-and allow comparison of the quality circles in ambulatory care in Germany with similar work in other countries. ${ }^{18}$ Meanwhile our simple form for collecting information about quality circles and our approach to feeding back the information may have relevance to the development of quality circles in ambulatory care in other countries.

We gratefully acknowledge the active participation of all the moderators of quality circles who made it possible to realise the concept. For valuable encouragement we are particularly indebted to Richard Grol of the Center for Research on Quality in Family Practice, Universities of Nijmegen and Mastricht. For their support we thank the managers and staff of the cooperating Associations of Statutory Health Insurance Physicians: erating Associations of Statutory Health Insurance Physicians: Klaus Bittmann, Johannes Hoffknecht, Hermann Holzhüter Christian Korn, Thomas Kriedel, Andrea Roth, and Sabine Schmidt. Comments on earlier drafts were provided by Wiebke Hellenbrand. This work was partly supported by grants from the associations of statutory health insurance physicians of Bremen Schleswig-Holstein, and Westphalia-Lippe. Part of this research with earlier results was presented at the first European forum on quality improvement in health care, March 1996, London. After submission of this paper the association of Schleswig-Holstein left the system, and was replaced by Soxony-Anhalt.

1 Grol R, Lawrence M. Quality improvement by peer review. Oxford: Oxford University Press, 1995.

2 Federal Association of Statutory Health Insurance Physicians. Guidelines of the Federal Association of Statutory Health Insurance Physicians on procedures for quality assurance according to $\$ 135$ par. 3 of the Social Security Code. Vol 5. Deutsches Arzteblatt 1993;90:B1148-51. (In German.)
3 Federal law on assurance and structural improvement of statutory health insurance. Bundesgesetzblatt 1992;59: 2266-334. (In German.)

4 Bahrs O, Gerlach FM, Szecsenyi J, eds. Quality circles in health care. Handbook for physicians in ambulatory care. 3rd ed. Köln: Deutscher Ärzte-Verlag, 1995. (In German.)

5 Gerlach FM, Bahrs O. Quality assurance by quality circles in general practice Strategies for implementation. Berlin, Wiesbaden: Ullstein Mosby, 1994. (In German.)

6 Szecsenyi J, Gerlach FM, eds. State and future of quality assurance in general practice. National and international perspectives. Stuttgart: Hippokrates, 1995. (In German.)

7 Gerlach FM, Bayer M, Römer A. Quality circles in ambulatory care: state of development and future perspectives in Germany. Int $\mathcal{F}$ Qual Health Care 1998;10: (in press).

8 Gerlach FM, Beyer M. Quality assurance in practice: results of an analysis of needs and wants among ambulatory care physicians in Bremen and Bremerhaven. Quality assurance in practice: results of an analysis of needs and wants among ambupractice: results of an analysis of needs and wants among ambulatory care physicians in Saxony-Anhalt. Göttingen: AQUA Institute for Applied Quality Improvement and Research in AQUA-Materials No III and IV).

9 Withdrawn.

10 Withdrawn.

11 Grol R, Mokkink H, Schellevis FG. The effects of peer review in general practice. $\mathcal{F} R$ Coll Gen Pract 1988;38:1013.

12 Grol R, Wensing M. Single and combined strategies for mplementing changes in primary care: a literature review. Int $\mathcal{F}$ for Qual in Health Care 1994;6:115-32.

13 Träder JM. Quality circle in Lübeck. Z Allg Med 1996;72:244-8. (In German.)

14 Roth A, Bittmann K. Evaluation of QCs in SchleswigHolstein. Ärztebl Schleswig-Holstein 1998;50:(in press). (In German.)

5 Likert R. A technique for the measurement of attitudes. Arch Psychol 1932;140:44-53.

16 Hartmann P, Bott U, Grüßer M, et al. Effects of peer-review groups on physicians' pr

17 Russell IT, Addington-Hall JM, Avery PJ, et al. Medical audit in general practice. I: Effects on doctors' clinical
behaviour for common childhood conditions. BMY 1992; 304:1480-4.

18 Lawrence M, Schofield T. Medical audit in primary care. Oxford: Oxford University Press, 1993. 
Appendix: Documentation form for quality circles (QCs) (feedback from moderators after every session)

\begin{tabular}{|c|c|c|}
\hline Name of moderator & QC theme & Site/date \\
\hline Duration of session (min) & Session $\mathrm{n}$. & $\begin{array}{l}\text { Additional experts/guests } \\
\text { (number/function) }\end{array}$ \\
\hline $\begin{array}{l}\text { Number of group members } \\
6\end{array}$ & Members present & $\begin{array}{l}8 \\
9\end{array}$ \\
\hline
\end{tabular}

\begin{tabular}{|l|l|}
\hline $\begin{array}{l}\text { Record of QC session } \\
\text { (topics/themes) }\end{array}$ & Duration \\
\hline $1 . .^{10}$ & 11 \\
\hline $2 . .^{12}$ & 13 \\
\hline $3 . .^{14}$ & 15 \\
\hline
\end{tabular}

\begin{tabular}{|l|l|}
\hline $\begin{array}{l}\text { Record of QC session } \\
\text { (topics/themes) }\end{array}$ & Duration \\
\hline $4 .^{16}$ & 17 \\
\hline $5 . .^{18}$ & 19 \\
\hline $6 .^{20}$ & 21 \\
\hline
\end{tabular}

Please evaluate the actual session from your point of view

( (1) = very satisfied, (6) = very unsatisfied)

I'm .... with the factual outcome.

(1) (2) (3) (4) (5) (6) 22

I was .... with the group atmosphere.

My overall judgement of todays session is.

(1) (2) (3) (4) (5) (6) 23

I feel that the participants were:

(1) (2) (3) (4) (5) (6) 24

I'm .... with my support to the group as a moderator.

(1) (2) (3) (4) (5) (6) 25

(1) (2) (3) (4) (5) (6) 26

Methods used (please indicate)

$\square_{27}$ interview of doctors/staff

$\square_{31}$ referral letter/reports

$\square_{35}$ practice visits

$\square_{28}$ patient interviews

$\square_{32}$ records

$\square_{29}$ computer based practice data

$\square_{33}$ oral report

$\square_{30}$ documentation sheets

$\square_{34}$ other methods:

$\square_{36}$ audio documentation

$\square_{37}$ video documentation

Presentation of data (please indicate)

$\square_{38}$ case reports (number of cases presented: ....) $\quad \square_{40}$ summarised data (statistics)

$\square_{39}$ other methods

\begin{tabular}{|c|c|c|}
\hline $\begin{array}{c}\text { Duration of own preparation } \\
41 \ldots \ldots \ldots m i n\end{array}$ & Material costs & Other costs (eg room, tel) \\
\hline
\end{tabular}

Results (eg goals, guidelines)/remarks/problems (if necessary, use back side or additional sheet)

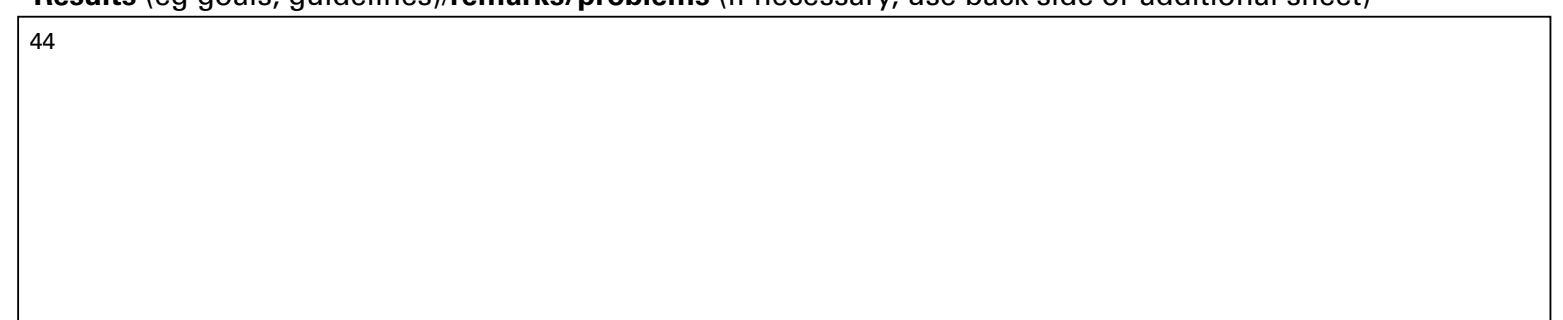

